\title{
A Counteractive Cognitive Approach to the Fixity of Colonial Categorical Borders in Miko Peled's The General's Son: Journey of an Israeli in Palestine
}

\author{
Khaled Karam*
}

This paper integrates cognitive literary criticism into postcolonialism in order to investigate an attribute of the mental aspect of the colonizer/colonized relation which is categorization. It adds a cognitive dimension to Fanon's theory of postcolonial psychoanalysis, making use of the toolkit of cognitive literary criticism. In "The Psychology of Colonialism and Postcolonialism: Cognitive Approaches to Identity and Empathy," Patrick Hogan (2015) indicates that cognitive postcolonialism offers a significant critique of mainstream postcolonial theory as several cognitivists reconsider the important questions raised by postcolonial theories and aim at formulating answers in the light of their current understanding of human cognition and mental processes (329-330). Thus, this paper adopts the cognitive theory of categorization in the treatment of Fanon's concept of reciprocal self-consciousness as an approach against the binary opposition of the self and the other.

It is relevant to point out that in the increasingly interconnected and multicultural contemporary world, introversion and self-centeredness have become obsolete. Therefore, in the light of this realization, it is significant to stress the idea that Fanon's concept of reciprocal self-consciousness, based on objective introspection and transcendently communal recognition, is capable of cultivating a flexibly inclusive mind that dissolve categorical boundaries between the self and the other. Thus, this paper emphasises the fuzziness of categories and dynamicity of the human mind which can challenge the monolithic, fixed borders between categories. Miko Peled's The General's Son: Journey of an Israeli in Palestine (2016) illustrates that reciprocal recognition can eliminate estrangement and penetrate boundaries, while otherness and autonomous self-consciousness sustain ghettoization and xenophobia and reconstruct artificial categorical borders. Peled emphasizes the idea that borders are fallible, unsustainable and transient because shared humanity and universal

* Lecturer in English Literature, Suez University, Egypt.

Cairo Studies in English - 2021(1): https://cse.journals.ekb.eg/ 
commonalities are more durable and transcendent than any artificial obstacles placed to categorize people according to race or nation.

In his memoir, Peled re-examines the concept of self-consciousness from the perspective of the colonizer; here the son of an elite Israeli leader undertakes a journey of self-discovery to transcend the distance separating the Israelis and Palestinians. He raises an outcry against the growing resistance to coexistence in the current discourse of many extreme rightists, Zionists and white supremacists. Through introducing voices from the opposite sides of borders, Peled's memoir argues that liberal-humanist cosmopolitanism necessitates a communal and non-categorical dialogue between the self and the other, hence adopting reciprocal self-consciousness as an antidote to the xenophobic and polarizing thoughts.

\section{The Process of the Cognitive Capacity of Categorization}

The cognitive capacity of categorization plays a crucial role in the individual's perception because the human mind spontaneously tends to schematize categories for everything it perceives. George Lakoff (1987) explains that "An understanding of how we categorize is central to any understanding of how we think and how we function, and therefore central to an understanding of what makes us human" (6). Therefore, the localization of an entity within a specific category guarantees a better understanding of its traits, relations with the world and its conceptual nature. Eleanor Rosch (2009) indicates that the mechanism of categorization is a universal method of perceiving life because the graded structure of categories affects considerations of the way people think and act. Moreover, Ellen Spolsky (2015, xxiv) confirms that "our understanding and use of fictions depend on our ability to manage a culturally established set of relationships between concepts and things, building on the innate ability to categorize." The capacity of categorization is, hence, fundamental to human cognition, adaptation and interaction with the surrounding environment and culture. The individual's cognition includes a matrix that is composed of a categorical structure of prototypes, so his appreciation of an identity draws on the components of this pre-established structure and its network of different and similar features.

The cognitive theory of categorization is based on the concept of prototype, setting a central model, then comparing and contrasting other members of the category with this prototype, showing to what extent they converge with or diverge from it. The prototype has a high cue validity acting as a central example at the middle of a radial structure, and it is used as cognitive reference index. 
Accordingly, the quality of an item is calculated by its proximity and relation to the central prototype. Mary Crane (2015) explains that the category "has a radial or gradient structure, with some members closer to and others farther away from the prototype"; thus, meaning is produced along a gradient of resemblance to a standard prototype or "best example" (17). The theory of prototype categorization differs from Saussure's theory of binary opposition in which the significance of an object is determined by difference. "The prototype theory is based on grading, pointing out significance through both converging resemblance and diverging differences" (Karam 2020). Thus, meaning is produced not only by a system of difference but also along a gradient of resemblance to a prototypical center. In this gradient structure, the prototype occupies the center with a basic level attached to it and occupied by items of close resemblance. Then, both the prototype and the basic level are encircled with a grade including subordinate members which share less attributes with the central prototype. These aforementioned grades, the prototype, basic level and subordinate members, are surrounded with peripheries occupied by items which are excluded because of divergence from the central identity of the prototype. The more distant from the center the member is, the less it possesses features typical of the category and vice versa.

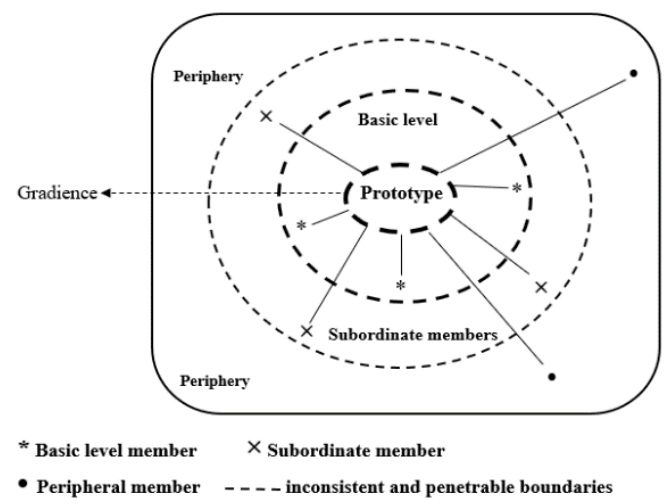

Figure 1. Gradience of members within the radial structure of the category (Karam 2020, 304).

Since one never gives up acquiring new data from his sensory system which need to be categorized and placed in their appropriate position in the conceptual catalogue of the mind, the whole structure of previously conceived categories should be modifiable in order to embrace new items and re-categorize the former 
accordingly. Thus, the capacity of categorization is characterized by flexibility and dynamicity because a category has no blocked or static boundaries. "Because the world doesn't stand still, the results of which is that its categories are permanently unstable, our brains revise categories creatively" (Spolsky 2010, 101). Accordingly, in the increasingly interconnected and multicultural contemporary world, concepts and meanings tend to overlap, challenging rigid boundaries among categories and entailing a flexible system of categorization which is more openable and inclusive. Therefore, categorization is

based on everyday experience and does not always lead to clear-cut categories with necessary and sufficient features. Rather more often than not, it leads to categories which have a clear center populated by prototypical members, and which have fuzzy boundaries that allow for marginal members which may even overlap with other neighboring categories. (Dirven 2005, 23-24)

Thus, categories are naturally inconsistent in the status of their incorporated members. A significant function of mental competence depends on one's capacity of continuous structuring and restructuring of categories as well as transcending fixed boundaries between them. Thus, according to the cognitive theory of categorization, the predominant concepts of fuzziness, change and adjustability, which are inherent in the construction of mental categories, deconstruct the fixity of categorical borders artificially set as a result of cultural or social conditioning.

\section{Reviewing Postcolonialism in the Light of the Cognitive Theory of Categorization}

Cognitively speaking, the colonial ideology overlays and imposes an overt, inorganic schema on the mind, devoid of gradience or flexibility as it is composed of only two categories, prototypical self and peripheral other with a solid mental barrier in between. Moreover, in this schema, the borders of categories are impenetrable. Thus, the idea of categorizing people according to race and nation is entrenched at the essence of the colonial discourse which places the Occident as a prototypical self or a central good example against which everything is projected and contrasted. "Every entity that deviates from 
this center is regarded as a poor example and located into the peripheral category" (Karam 2020, 304).

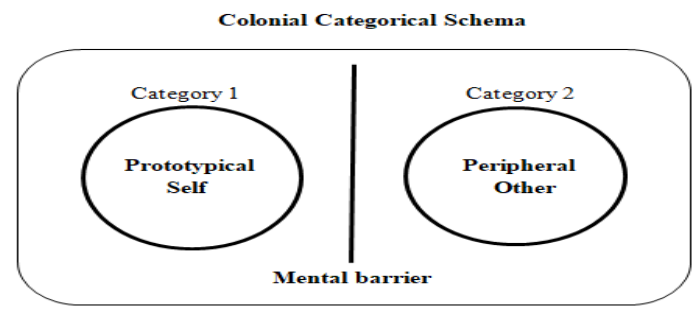

Figure 2. Colonial categorical schema (Karam 2020, 305)

The idea of Eurocentrism is partly founded on the theory of categorical prototype, but it rejects the dynamic and inconsistent nature of the mental process of categorization. The colonial mentality rejects surpassing borders set between the static categories of race, colour and nation. The idea of static stereotyping, propagated by the colonizer, is utilized to reinforce borders between these categories. Therefore, the paper argues that to colonize is to categorize; colonization is contingent upon rigid, unmodifiable categorization, so colonialists tend to be categorists in their thought.

Drawing on cognitive theories, the process of categorization proves to be fundamental to human cognition and all forms of interaction, yet categories are inconsistent in the status of their constituent members. "Categories are composed of a flexible gradation and overlapping, fuzzy boundaries which are penetrable, allowing mobility of members" (Karam 2020, 305). Therefore, the duality of the colonial schema and the fixity of the concept of binary opposition, rooted at the core of the ideology of colonialism, are inconsistent with the cognitive nature of the mental process of categorization. In other words, the inflexibility of the colonial mentality contradicts the elastic nature of human cognition.

Several postcolonial critics have attempted to deconstruct such nonobjective and impractical fixity of colonially based categorization. Bhabha's concepts of hybridity and ambivalence "indicate the dismembering of fixed and 'pure' categories which is a symptom of the borderless world we live in" (Sethi 2011, 11). He illustrates the move away from "the singularities of 'class' or 'gender' as primary conceptual and organizational categories," resulting "in an awareness of the subject positions [...] that inhabit any claim to identity in the modern world" (Bhabha 1994, 1). Thus, Bhabha emphasizes the concepts of dynamism and inconsistency in the conceptual categories of gender and race. Said (1979a) 
indicates that colonial knowledge is filtered through cultural and categorical bias, so it is devoid of objectivity.

\begin{abstract}
When one uses categories like Oriental and Western as both the starting and the end points of analysis, research, public policy ... the result is usually to polarize the distinction - the Oriental becomes more Oriental, the Westerner more Western-and limit the human encounter between different cultures, traditions, and societies. (Said 1979a, 45-46)
\end{abstract}

Therefore, the uncompromising orientation of colonial discourse hinders reciprocal recognition and restrains the flexible nature of mental workspaces responsible for the processing of categorization. However, Said (1994) indicates that "the old categories, the tight separations, and the comfortable autonomies" have become obsolete because of "the tremendously powerful upheavals" of the last decades of the $20^{\text {th }}$ century which witnessed "the breaking down of barriers [...] the drift across borders, the looming problems of immigrant, refugee, and minority rights in the West" (53).

According to Young (2016) colonialism is theoretically embodied and rationalised through the category of race. He indicates that the ideological formation of colonialism works on the basis of racial and ethnic identification; thus, "the distinctive characteristic of such colonialism was that race functioned as its primary ideological legitimating and organizational category" (Young 2016, xviii). However, he points out that the contemporary ideology of multiculturalism emphasizes "the traditional ideas of identity as a positive category in order to accommodate diversity" (x). Thus, postcolonial intellectuals consider the concept of fixity of categorical distinction non-positive and challenge the very concept of static identities. Accordingly, the cognitive approach to colonial categorization opposes the notions of categorical fixity embedded in the duality of the self and the other in order to "rediscover transnational space connections based on diffusion and mobility" (Sorensen 2018, 13). Hogan (2015) uses the recent knowledge of cognitive science to examine the colonial mentality and perception of identity from a cognitive perspective. He distinguishes between one's "practical identity" and one's "categorial identity" (335). He describes the former as "a complex of propensities and competencies that enable one's interaction with others in the social world. It is the integrated interrelation of cognitive structures and processes" (335). Categorial identity, in contrast, "is a sort of labeling with a 
very minimal definition. The labeling can be a matter of race or nationality" (335). Categorial group division leads people to regard their in-group members as more favorable and out-group as unfavorable, so categorical identity represents the cognitive operations taking place in the colonial mind to "develop these divisions in thought and action" (338). Accordingly, while practical identity is flexible, adaptive and inclusive, categorial identity is stiff, bigoted and separatist. The practical identity fosters mutual integration which can be eradicated by the growth of categorial identification.

Accordingly, postcolonial thinkers maintain that the analysis of colonial ideology entails reconsidering categories in order to recognize their overlapping nature and deconstruct the rigidity of artificial dissections such as Occident/Orient, self/other and so on, stressing the idea of relationality and fluidity rather than insulating boundaries. "Thus, for the cognitive postcolonial approach, to decolonize means to de-categorize the colonial ideology, drawing insight from current cognitive studies" (Karam 2020, 306).

\section{Fanon's Concept of Reciprocity as a Counteraction to the Fixity of Categorical Borders}

Fanon (2008 [1952]) criticizes the colonial discourse which depends on an understanding, constructing the world in terms of fixed categories. He points out the fact that as a result of the prevalence of the colonial discourse, "some individuals make every effort to fit into pre-established categories" which are always determined by the superior colonial power (Fanon 2008, 58). This categorical perception is based on both discrimination and identification. It identifies with the central prototypical self, the Occident, and discriminates between it and the deviant, peripheral other. Fanon argues that one reason for the alienation between people of different races is due to a rigid psychological categorization; "[t]he Negro enslaved by his inferiority, the white man enslaved by his superiority alike behave in accordance with a neurotic orientation" (42). Thus, the colonially conditioned mind constructs a personality one-sidedly, rejecting any intersubjective or reciprocal process because its concept of identity is mainly discriminatory, "employing the very categories of perception" (154). In an opposition to this thought, Fanon regards the relation between the self and the other as a reciprocal and dynamic communication necessitating mutual recognition which is capable of transcending categorical borders.

Fanon adopts the Hegelian concept of reciprocal self-consciousness in his treatment of the problematic categorization of the self and the other in order to prove the impracticality and non-objectivity of the colonial mentality and its 
entrenched, categorical schema. Fanon's book, Black Skin, White Masks (2008[1952]), includes an obvious engagement with the master/slave and self/other dialectics discussed in Hegel's Phenomenology of Spirit (1977 [1807]). This study argues that Fanon's treatment of Hegel's concept of reciprocal self-consciousness deconstructs fixed categories, thus encouraging a fluid relationship between the colonizer and the colonized and transcending the fixity of the binary opposition. Hegel's concept of mutual recognition depends mainly on a process of reciprocity and true awareness of the self as well as the recognition of the other's awareness of one's self, creating interpersonal unity. Moreover, when each side negates the categorical differences that serve to distinguish one human being from another, each individual becomes capable of recognizing the other as being of the same common shared human category as himself.

Fanon agrees with Hegel about the need for the other to develop an actual, unified self-consciousness, but he adapts Hegel's abstract theory of selfconsciousness into a more practical guideline. He explains that at the foundation of Hegelian dialectic "there is an absolute reciprocity which must be emphasized. It is in the degree to which I go beyond my own immediate being that I apprehend the existence of the other as a natural and more than natural reality" (Fanon 2008[1952], 169). He argues that Man is human only to the extent to which he tries to "impose his existence" on another fellow human being in order to be recognized by him (168). The emphasis on the word, "impose," bears a key significance in Fanon's treatment of Hegel's concept of reciprocal self-consciousness, implying effectiveness and challenge. One should not only recognize himself and perceive his image in the eyes of the other but also compel the other to recognize him and respect his true identity. "It is on that other being, on recognition by that other being, that his own human worth and reality depend" (168-169). Moreover, each side should release his self-consciousness from the blinding, categorical subjective estimation of the self towards a more openminded inclusive recognition of the other. "Similarly, the other is waiting for recognition by us, in order to burgeon into the universal consciousness of self" (169). Fanon also appropriates Hegel's notion of reciprocal self-consciousness by arguing that adherence to national culture and race is indispensable in this struggle so that the colonial subject can recognize the other without losing his own identity. Thus, Fanon's concept of objective, reciprocal self-consciousness is capable of eliminating categorical borders between the self and the other because it engenders self-assertion through contact and universal communality. 
Fanon considers the categorical borders, fixed by the colonizer between identities, to be an impediment in the way of objective reciprocity. "The colonizer defines himself by defining the other and by drawing comparison, but the other way round is blocked for the colonial subject who is deprived of the same opportunity of comprehensive self-consciousness" (Karam 2020, 308). Fanon indicates: "If I close the circuit, if I prevent the accomplishment of movement in two directions, I keep the other within himself. Ultimately, I deprive him even of this being-for-itself" (169). Here, he censures the rigidity of the colonial categorical schema and the impenetrable barrier, entrenched within its structure. Thus, in this case, the Hegelian concept of reciprocal selfconsciousness cannot be fulfilled when cognition is confined to one-sided image or schema. "The only means of breaking this vicious circle that throws me back on myself is to restore to the other [...] The other has to perform the same operation" (169). Both Fanon and Hegel emphasize that action from one side only is insufficient because reciprocated recognition can only be brought about by means of faithful endeavors from both sides.

Fanon argues that the colonial consciousness is non-dialectical at its core as it is rigidly categorical; therefore, it denies the colonial subject such privilege of true self-realization and interrelation. Because of these categorical obstacles, real self-recognition needs a risk and hard struggle for freedom from the shackles of the non-objective colonial system of categorization. For Fanon, one should challenge categorical boundaries and fight for intersubjective self-assertion and transcendently mutual recognition. According to the categorical colonial mind, in order to be embraced within the privileged category, one has to assume resemblance with the central Occidental prototype; otherwise, he is alienated and placed outside the category, in the peripheries. Fanon rejects this categorical schema and urges the colonial subject to penetrate the discriminatory borders not through blind mimicry but through reciprocity which depends on recognizing one another as equal human beings sharing universal homogeneity.

Fanon's concept of reciprocal self-consciousness corresponds with the cognitive ideas of fuzziness and adjustability of categories as it deconstructs the fixity of categorical boundaries between the self and the other, created by the colonial discourse. Moreover, it is anti-categorical on the basis of culture or race. For Fanon, identity is dynamic and relational, defying the immutability of the colonial unilateral categorization. Accordingly, his point of view about reciprocal self-consciousness is congruent with the cognitive theory of categorization which emphasizes the fuzziness and inconsistency of categories. Therefore, the categorical mentality internalized - as a result of colonial 
hegemony - in both the mind of the colonizer and the colonized needs to be decolonized. In other words, "decolonization necessitates de-categorization which means re-examining the fixed racial, ethnic and national categories and their in-between boundaries, reinforced by the colonial ideology" (Karam 2020, 309). Fanon points out that reciprocity is attainable and achievable if the two sides surpass and negate the manifold categorical discrepancies detaching them and when the center and periphery are engaged in operative interaction as both initiators and recipients of influence.

\section{Peled's Memoir as an Embodiment of Anti-categorical Reciprocal Self- consciousness}

Since Peled's creative nonfiction accounts for refugeeism, migration, settlement, and displacement psychologically and socially, a cognitive postcolonial analysis contributes to the perception of the intercategorical advancement through race, ethnicity and nation, embodied in his memoir. Studies of diasporas, transnational citizenship and mobility offer "trenchant critiques of the bounded and static categories of nation, ethnicity, community, place and state" (Hannam et al. 2006, 10). Thus, the cognitive postcolonial approach to writings about expatriation and settlement gives insight to the reader to perceive the fuzziness and adjustability of categories of identity, nation and race. In his memoir, Peled (2016), a peace activist, investigates how the ethnostate of Israel is categorical about the concept of nativity, authorizing ethnic and religious definition of citizenship. He attempts to deconstruct the categorical system of Zionism by adopting reciprocal self-consciousness and undertaking the enormous task of healing the rift between the self and the other as his lifetime mission. In his intercategorical book, Peled merges travel narrative into memoir and interweaves his personal experience with public history.

Peled's engaging narrative of transformation arises from a personal tragedy and wise meditation on the history of his nation. His memoir traces the development of his self-consciousness and disillusionment with the state of Israel. His conversion from Zionism to anti-Zionism parallels liberating his mind from ethnically categorical thoughts. He was born in Jerusalem in 1961 into a prominent Zionist family. His father was a distinguished military leader and a Knesset member. His attitude to Zionism and the Palestinian/Israeli conflict witnessed a significant transformation after his niece, Smadar was killed in a suicide bombing attack. He indicates: "This wrenching tragedy is the starting point of my personal journey, a journey that transformed my heart" (17). This calamity has pushed him into a bold examination of his Zionist beliefs, Israel's 
history, and the political circumstances which fueled the suicide bombers to blow themselves up murdering people indiscriminately. Instead of adopting revengefulness and hostility blindly, he decides to meet the people on the other side of the separation wall, regarded as the enemies of his country. He gradually recognizes that his deeply rooted categorical system of the self and the other or the good and the evil contradicts what he actually witnesses in his actual communication with Palestinians.

Peled's journey sets off from California when he joins the Jewish-Palestinian dialogue group there. Listening to Palestinians, the other, he declares that he "learned of mass expulsions, massacres, and grave injustices" (20). He confesses his deep sorrow because he has not been in possession of the full truth. He admits, "The willingness to accept another's truth is a huge step to take" (141). This corresponds to Fanon's idea that ultimate and comprehensive selfconsciousness can never be realized without objective communication with the other. Peled goes beyond his own immediate being and colonially fixed categories in order to perceive the existence of the other as a natural and actual reality. Thus, he adopts an intercategorical approach that reconsiders the relationships across the rigid boundaries of categories, emphasizing their intersecting nomenclature. He decides to travel alone to the occupied Palestinian territories, paying no heed to warnings from all his acquaintance. Through his faith in the possibility of reciprocal recognition, he decides to conquer his fear of Arabs which has infected his thought and stiffened his perception of categorical boundaries between the self and the other. He declares: "I confronted what emerged in my mind as the greatest obstacle to peace: fear of the 'other,' [...] Through centuries of experience and conditioning, fear had become almost inseparable from my culture" (20). Peled replaces this fear by trust and regards his life as "the tale of an Israeli boy, a Zionist, who realized that his side of the story was not the only side and chose to cultivate hope in a situation most call impossible" (20). He believes that his experience of reciprocity can offer a model for reconciliation, capable of eradicating the fear of the other, deeply implanted in the minds of both sides.

Peled, "at first terrified of reaching out to Palestinians because of the false reports he was, since childhood, given of them, realizes the insanity of remaining enemies of a people he has had no opportunity to truly know" (Walker 2016, 12). His interaction with Palestinians deconstructs his preconceived idea about Arabs and encourages him to go further in his communication with the people who have the same right as him to exist in this land. "He begins to understand the danger inherent in living in ignorance of the so-called 'other"' (12). He 
comprehends that he would not reach a full, objective and reciprocal selfconsciousness unless he overcomes such illogical fear of the other and the separatist, categorical thought of the colonizer.

In mourning his niece, many politicians came to Peled's family house to offer condolence; among them was Ehud Barak. Peled confronted Barak with these frank and eye-opening words: "Why not tell people that this and other similar tragedies are taking place because we are occupying another nation and that in order to save lives the right thing to do is to end the occupation and negotiate a just peace with our Palestinian partners?" (Peled 2016, 124). Here, Peled's words raise a brave outcry demanding communication via categorical borders and establishing a bridge of mutual understanding. Through an objective insight and a capability of transcending personal prejudices, Peled manages to reach the essence of the problem, the "Israeli occupation," and concludes a drastic solution summed up in "just peace" (124 - 125). Peled is endowed with open-minded selfconsciousness capable of objective self-exploration and tolerance of the other; therefore, he manages in this stage of his life to gradually abandon the longadopted illusions and preconceived categorical fixity.

At the beginning of his journey to Arab Palestine, Peled acknowledges the huge psychological rift which has separated him from the Arabs as a result of the narrow-minded categorical system of colonial apartheid. He admits: "There was 'us' and there was 'the Arabs,' and we might as well have been living on different planets" (131). The propaganda, disseminated by the state, has reinforced the concept of Jewish supremacy and the preconceived categorical thought that Arabs are poor and less developed. Therefore, he has internalized many stereotypes related to the inferior image of Arabs. The first step of his journey toward the other is to find people with whom he can talk and get rid of the stereotyping thinking. He comes across American-Arab Anti-Discrimination Committee and starts to attend meetings including American Jews and Palestinians. He confesses: "at first I couldn't tell for sure who was who," emphasizing the artificiality of categorical border between the self and the other (137). This was first time for him to be in a place "where Jews and Palestinians exist as equals" (138). He indicates that the opportunity which enabled them to talk and look each other in the eye "made a huge difference" (138). Consequently, he decides to abandon his past knowledge and question its credibility so that he can explore the unknown territory of the other and adjust his perceived categorical schema accordingly. He realizes that "crossing the line to understand the 'other' point of view" will not be welcomed by everyone, but he refuses to surrender to discouragement (143). 
Peled joins Rotary Club in San Diego and forms a partnership with a Muslim Palestinian called Nader Elbanna. Although they have very little in common, they manage to cooperate to do something good for both Israelis and Palestinians. In Nader's company, Peled travels to Israel intending to cross borders to the Arab territory to deliver medical equipment. When he finds himself surrounded by Arabs in a Palestinian town for the first time in his life, he expresses his initial fears saying, "I had to exercise enormous control to prevent it from consuming me" (156). However, he discovers that they are eager to help him and make him feel welcome though they know that he is a Jew. He realizes that his fear of the other is unjustified and indicates that "these people are nice" (156).

Peled expresses his keen determination to get rid of this unreasonable fear completely. He argues that peace can only be achieved when there is mutual trust, and "that can only come through individuals reaching across, if not breaking down, the wall of fear" (158). However, Israeli security laws make it impossible to reach out to the other side, sustaining the colonial categorical system. Peled believes that "the security reasons cited by the Israeli officials for the wall and the checkpoints, which were keeping us from visiting and getting to know people on the 'other side,' were merely scare tactics designed to prolong the conflict" (158). In an act of defiance to the apartheid system of Zionism, he urges both Palestinians and Israelis to tear the veil of fear and allow the other to look through it.

Peled declares his determination to defy Zionist authority pertaining to the occupation by continuing his visits to the occupied land. Peled manages to identify himself with the other, feeling the same pain of having his land confiscated and his voice violently oppressed. His visits to the Palestinian villages have erased the psychological distance between him and the other and reinforced his trust in his new Palestinian friends. He possesses an impartial mind which manages to revise and modify his previous, categorical schemas according to his new perception. After he is released from detention for visiting the prohibited Arab lands, he meets his Palestinian friends again and declares: "My own people had arrested me for doing something good. My disillusion with Israel had sunk to a new low" (178). He insists on finding an opportunity to interact further with all the slices of the Palestinian society, protesters, nonviolent activists, former prisoners, leaders of resistance and even children. He believes that it is important for him to experience the occupation from inside in order to examine the validity of its categorical apartheid system and explore its environmental, social and economic effects. 
Peled and his Palestinian friend Jamal travel throughout the West Bank, and over the years he has introduced him to many excellent people beyond the separation wall. He states: "Then we'd all sit and have coffee or juice, and I never felt more comfortable and welcome than I did in these random meeting with Palestinians who had fought and paid dearly for the sake of freedom" (199). He illustrates how he manages to live in a peaceful communion with the other after he has given himself an opportunity to explore himself beyond the veil of preconceptions and identify with the other through nonbiased and open-minded self-consciousness. His actual interaction with the Palestinian environment and people enables him to reconsider his preconceived categories and transcend the psychologically and physically fabricated borders of the categorical system of the Zionist regime toward what Fanon calls "a supreme good that is the transformation of subjective certainty of [one's] own worth into a universally valid objective truth" (Fanon 2008[1952], 170).

Peled's close contact with the other leads to his disillusionment with the stereotypical categories propagated by the Israeli conditioning policy. He decides to visit Gaza to supply some medical equipment to the besieged Palestinians. He openly blames Israel for the state of devastation in Gaza. His visit to the Palestinian villages enables him to draw an objective contrast between conditions in the opposite sides of the separation wall. Sparse population of settlers occupies the vast dispossessed land, while the "rightful owners" (Peled 2016, 164) of the land are pushed into small, underserved ghettos of overcrowded population, revealing an unjust apartheid system based on faulty categorization. Witnessing the immense investment in settlements, he expresses his belief that when Zionists talked about the two-state solution, "they were lying" (247). Peled describes the separation wall as "the ugly concrete structure" (174) and compares Israeli settlements to an "open wound" in a peaceful land (213). He also points out that the Israeli apartheid system has depended on "ethnically-based oppression for decades to achieve its goal of creating a Jewish majority in Israel/Palestine. Nowhere has this oppression been more evident than in Gaza" (181). Thus, the colonial system of Israel works to impose its rigid categorical segmentation on the demography of the land, setting the Jewish minority as a central prototype and the Palestinian majority as a peripheral entity by rendering them invisible. Peled's reciprocal self-consciousness defies and deconstructs this separatist system by bringing the marginalized to the center of his narrative and categorical schema.

Realizing the inhuman siege of Gaza, he expresses his feeling of injustice and disappointment at the loss of humanity, saying: "I felt ashamed of the country I 
used to be so proud of" (191). He regrets that his people "were holding the keys to the gate and would not let anyone enter" (191). Thinking of just peace, he attempts to make amends by building bridges that can allow an ongoing communication between Palestinians and Israelis in order to open "a crack in the walls that surrounded Gaza" (180). Although the narrator fails to cross the borders to Gaza, he manages to cross the psychological border between himself and the other.

Peled struggles not only to communicate with the other but also to oblige the other to recognize him. He manages to convince his Palestinian friends that Israelis are not all Zionists or enemies and positively imposes his existence on the other in order to heal the rift. Thus, he manages to make his Palestinian friends transcend the categorical fixity of the self and the other through objective reciprocity and confidence. He also condemns the apartheid system of Israel for denying the Palestinians the right of having a comprehensive and reciprocal selfconsciousness because of the separation wall and discriminatory policy. He confesses that the Zionist regime keeps the other within himself, blocks all paths toward reciprocal recognition and hinders dialectical interaction between the self and the other. The occupation's consciousness is unchangeably categorical and non-dialectical at its core, so it deprives the colonized of such privilege of selfrealization. In such environment, developing an actual self-consciousness on both sides of the wall becomes impossible.

Peled follows Fanon's trans-categorical reciprocity, so he takes the risk, passes gates and ventures into the Arab lands. Peled's description of the lifestyle of the Palestinians draws common connections between the way Palestinians struggle and the role assigned by Fanon for the subaltern. They do not surrender to despair; on the contrary, they impose their existence, as recommended by Fanon, through "uncovering resistance, opposition, challenge" (Fanon 2008, 173). "They managed to create the semblance of normalcy in this cramped and confined existence Israel permitted them" (Peled 2016, 199).

Peled indicates that Palestinian Muslims and Jews used live side by side before Zionism has interfered and built an ethnic wall between them, founded on racial hatred and antagonism. After he comes into close contact with Palestinians, he concludes: "Because the day-to-day details of our lives are the same [...] This was how I became convinced, beyond any words or ideology, that we are similar and that we can prosper together once we overcome the bitter, brutal regime of Zionism" (199). He indicates that the Palestinian people are hospitable, and they always welcome guests with open arms regardless of their race or origin. As a result of his scrutiny of the Palestinian environment, he 
discovers that separation borders are at odds with the nature of the land. $\mathrm{He}$ admits:

Palestine's landscape is the kind that beckons you to open doors and its people are hospitable and always welcome you with open arms [...] Yet the settlers and their protectors have chosen to impose themselves on this land and its people, to take the land by force and close themselves within fortified ghettos, called settlements. (213)

He confirms that this land "is at least as much theirs as it is mine-if not more" (232). He acknowledges that the apartheid system is based on a categorical thought, dividing people into ghettos of Jewish and non-Jewish population. While it builds walls to push the Palestinian natives to the peripheries, dispossess them and deny their nativity, it opens borders to Jewish migrants from all over the world, treats them as natives and builds settlements for them on the confiscated Palestinian lands. Here, Peled exposes the double-standard policy of the Zionist regime which is based on faulty categorization of nativity. LeBlanc (2013) explains this misconception: "These exclusions depend upon categories of essence in which those who are not like us are deemed not only outside the community but also outside of the possibility of community" (86). Said (1979b) also points out these "exclusionary categories" which "systematically and juridically make it impossible [...] for the Arab Palestinian to return, be compensated for his property, or live in Israel as a citizen equal before the law with a Jewish Israeli" (49). Peled, here, tackles the idea of nativity, deconstructing the rigid Zionist categorical schema of native and non-native. He argues that these fixed categories are fabricated and artificial because they are against the all-embracing nature of the land and its actual demography.

Peled's journey of self-exploration culminates in a brave confession. He tells his Zionist brother-in-law, "you know just as well as I that we are all settlers, and all of Israel is occupied Palestine" $(2016,249)$. Thus, he confirms that all Israelis are colonists, and Palestinians are the true natives of the land. Abulhawa (2012), a Palestinian American writer and activist, regards this brave confession as a true "personal triumph" and writes, "Because it was in that admission that Miko Peled became a man I could embrace as a brother and fellow countryman." Peled's ability to overcome the categorically racist ideology of Zionism wins him the brotherhood of the other, sharing one universal category of humanity. His elastic capacity of categorization and recategorization enables him to 
transcend the colonially fabricated wall of denial and fear of the other; consequently, he admits the existence of Palestinians and denounces occupation.

Peled believes: "Demanding freedom and equality for our friends [Palestinians] [...] and indeed expecting it, is tough but realistic" $(2016,252)$. Thus, he courageously admits the existence of the other according to Fanon's concept as "a natural and more than natural reality" (Fanon 2008, 169). Because he refuses to adopt the story of the Israeli side for granted, he realizes the meaning of one's true self-consciousness which transcends narrow stereotypes and overcomes xenophobia. Consequently, he raises a crucial question and addresses it to his people: "Why were we demonizing these people, why do we fear them when we should embrace them?" (Peled 2016, 242).

Peled laments the fact that few people have developed true friendships across the segmentation wall as he has done. In his perception of people around him, the colonial dual categorical schema of the self and the other is replaced by an all-embracing unitary category, humanity. His open-minded, reciprocal selfconsciousness enables him to perceive the other as actual existence. The contact with the other provides him with new concepts, and as a result he discovers that his preconceived categories need to be adjusted in the conceptual inventory of his mind according to the newly acquired data and knowledge. Thus, cognitively speaking, Peled's mind copes with the resilient nature of the human mind and the dynamicity of the capacity of categorization innately admitting no closed, fabricated or fixed boundaries between categories. Peled, a devotee of reciprocal communication, sets an example for many people whose blind prejudice blurs their insight and stiffens their capacity of categorization.

In conclusion, this study stresses the inability of traditional categories, colonially structured, to account for the multiple and dynamic understandings of mobility and transactions across borders in the contemporary world. It stresses the need to think beyond borders of categories, adopting Fanon's concept of reciprocal self-consciousness as a nondiscriminatory and anti-categorical remedy. In his extra-categorical and extraterritorial memoir, Peled points out the idea that the recognition of the concept of shared humanity and reciprocity can cultivate minds capable of overcoming the fixity of the colonial system of categorization and developing an ongoing, re-categorizing cognition which flexibly transcends rigid categorical borders in order to encompass all rather than exclude or marginalize fellow human beings as the other. Unlike most literature about migration and mobility which demonstrates movement toward the Occident, Peled here draws his deliberate experience of crossing the border to the opposite direction, the Orient. Peled, an American Israeli, goes on a journey 
from California and Israel to Palestine, West Bank, thus moving from the Occident to the orient.

Peled's memoir features a transcendental journey of self-discovery and ideological transformation. His close contact with the other leads to his disillusionment with the stereotypical categories propagated by the Israeli conditioning policy. He discovers how one's native land becomes uninhabitable by a brutal occupation, and in this case, refugees are confronted with borders which curb their freedom of movement and quest for a respectable human life. Refugees, crammed in ghettos in the peripheries of their own homeland, are confronted with physical and psychological barriers set and internalized by the categorical system of colonial powers, separating them from their fellow human beings who regard them as a threat to their superior state and security. However, Palestinians stick to their land and resist the separation wall. Thus, Peled demonstrates the struggle of refugees or the subaltern for reciprocal recognition beyond categorical boundaries.

The ultimate success of the protagonist to cross borders and efficiently integrate into the community of the other corresponds with the cognitive approach to the categorical ideology of colonialism, emphasizing the flexible and crossable nature of perceived borders between cognitive categories. Peled indicates that the categorical borders which separate people of different race and colour are artificial and passable; therefore, they can be cognitively transcended by individuals who are capable of open-minded reciprocal self-consciousness. He gives a sense of hope through the portrayal of individuals from the opposite sides of the border who manage to cross ethnic boundaries and reach out to communicate with the other constructively.

Peled investigates the psychological basis of the insistence on maintaining borders. He explains that the fear of the other is the most powerful motive beyond division and stiff categorical thinking, inflaming extreme racism and fanaticism which thrive on emphasizing differences. People tend to categorize anything that seems different and unfamiliar as unsafe, so the other is estranged and barred behind walls. However, when they are able to step back from this exaggerated fear and reassess it deliberately in the light of shared human values, they can set themselves free from the polarized, categorical demagoguery, inciting fear. Therefore, Peled raises an outcry to overcome this fear in order to tear down borders, coexist and communicate positively on the basis of reciprocal self-consciousness. Getting rid of this fear restores the natural resilience of the human mind that is multi-categorical and receptive. He also emphasizes the obsoleteness of the mentality of racist demagogues and fear mongers 
manipulating people's mind and playing on their fear of what is unfamiliar and inaccessible to arouse visceral response rather than reasonable reaction to people of different ethnicity or colour. He concludes that the natural evolution of human communities depends to a great extent on the interdependence, diversity and adaptability of their conceptual categories of citizenship and belonging. Thus, the nationalist, nativist and supremacist thoughts must give way to the unitary concept of humanity as a global category. Societies which persist in racial categorization and maintain borders are expected to perish or undergo an inevitable retrogression in the future.

\section{Works Cited}

Abulhawa, Susan. 2012. "Book Review: Miko Peled Sets the Record Straight on Palestine's Dispossession." The Electronic Intifada, Nov. 29. https://electronicintifada.net/content/book-review-miko-peled-sets-recordstraight-palestines-dispossession/11950.

Bhabha, Homi. 1994. The Location of Culture. London: Routledge.

Crane, Mary. 2015. "Cognitive Historicism: Intuition in Early Modern Thought." In The Oxford Handbook of Cognitive Literary Studies, edited by Lisa Zunshine, 15-33. Oxford: Oxford University Press.

Dirven, René. 2005. "Major strands in Cognitive Linguistics." In Cognitive Linguistics, edited by Francisco de Mendoza and M. Peña, 17-68. Berlin: Walter de Gruyter.

Fanon, Frantz. (1986) 2008. Black Skin, White Masks. Translated by Charles Markmann. London: Pluto Press.

Hannam, Kevin, Mimi Sheller, and John Urry. 2006. "Editorial: Mobilities, Immobilities and Moorings." Mobilities 1(1): 1-22.

doi.org/10.1080/17450100500489189.

Hegel, Georg W. F.. (1807) 1977. Phenomenology of Spirit. Translated by A.V. Miller. Oxford: Oxford University Press.

Hogan, Patrick. 2015. "The Psychology of Colonialism and Postcolonialism: Cognitive Approaches to Identity and Empathy." In The Oxford Handbook of Cognitive Literary Studies, edited by Lisa Zunshine, 329-346. London: Oxford University Press.

Karam, Khaled. 2020. "Reciprocal Self-consciousness as an Antidote to the Fixity of Categorical Borders in Mohsin Hamid's Exit West." Neophilologus 104 (3): 301-19. https://doi.org/10.1007/s11061-02009639-5. 
Lakoff, George. 1987. Women, Fire, and Dangerous Things: What Categories Reveal about the Mind. Chicago: University of Chicago Press.

LeBlanc, John. 2013. Edward Said on the Prospects of Peace in Palestine and Israel. New York: Palgrave.

Peled, Miko. 2016. The General's Son: Journey of an Israeli in Palestine. 2nd ed. Charlottesville: Just World Books.

Rosch, Eleanor. 2009. "Categorization." In Cognition and Pragmatics, edited by Dominiek Sandra, Jan-Ola Ostman and Jef Verschueren, 42-52. Amsterdam: John Benjamins.

Said, Edward. 1979a. Orientalism. New York: Vintage Books.

----. 1979b. The Question of Palestine. New York: Vintage Books.

----. 1994. Culture and Imperialism. New York: Vintage Books.

Sethi, Rumina. 2011. The Politics of Postcolonialism: Empire, Nation and Resistance. London: Pluto Press, 2011.

Sorensen, Diana. 2018. "Editor's Introduction: Alternative Geographic Mappings for the Twenty-First Century." In Territories and Trajectories: Culture in Circulation, edited by Diana Sorensen, 13-31. Durham: Duke University Press.

Spolsky, Ellen. 2010. "Making 'Quite Anew': Brain Modularity and Creativity." In Introduction to Cognitive Cultural Studies, edited by Lisa Zunshine, 84102. Baltimore: The John Hopkins University Press.

-----. 2015. The Contracts of Fiction: Cognition, Culture, Community. New York: Oxford University Press.

Walker, Alice. 2016. Forward: The Sanity of Friendship. The General's Son. By Miko Peled, 11-15. Charlottesville: Just World Books.

Young, Robert. 2016. "Preface to the Anniversary Edition." Postcolonialism: An Historical Introduction, ix-Xxv. Chichester, UK: John Wiley. 